\title{
COMMUNICATIONS
}

\section{ANALYSIS OF KOŠICE METEORITE BY MÖSSBAUER SPECTROSCOPY}

\author{
Jozef Sitek — Július Dekan — Katarína Sedlačková *
}

\begin{abstract}
The ${ }^{57}$ Fe Mössbauer spectroscopy method was used to investigate iron-containing compounds in town Košice meteorite fallen on the territory of Slovakia in February 2010. The results showed that the Mössbauer spectra consisted of magnetic and non-magnetic components related to different iron-bearing phases. The non-magnetic phase includes olivine, pyroxene and traces of $\mathrm{Fe}^{3+}$ phase and the magnetic component comprises troilite (FeS) and iron-rich Fe-Ni alloy with hyperfine magnetic field typical for kamacite. Samples from meteorite were obtained in powder from different depths to inspect its heterogeneous composition. The content of kamacite increases to the detriment of troilite from the surface toward the centre of the sample. Measurements at liquid nitrogen temperature confirmed phase composition of investigated meteorite. Main constituent elements of studied samples were also determined by X-ray fluorescence analysis.
\end{abstract}

K e y w o r d s: Mössbauer spectroscopy, Košice meteorite, phase analysis, chondrite

\section{INTRODUCTION}

Iron-bearing minerals form important components of all meteorites can carry a lot of information about their history. ${ }^{57} \mathrm{Fe}$ Mössbauer spectroscopy is useful for their characterization because it provides valuable information on the atomic environment of iron nuclei and hence leads to direct identification of iron compounds and their chemical states. It has been shown that different classes of meteorites exhibit characteristic shapes of Mössbauer spectra and when an appropriate evaluation procedure is applied, a fingerprint Mössbauer analysis can be quickly made to obtain a reliable classification of meteorite $[1,2]$.

The basic composition of ordinary chondrites is well known from the analysis of different meteorite falls $[3,4]$. Ordinary chondrites exhibit Mössbauer spectra comprising 4 major components corresponding to 4 iron-bearing minerals like olivine, pyroxene, troilite and metallic alloy (Fe-Ni alloy, kamacite/taenite). The content of metallic fraction varies between 10 and $25 \%$ for $\mathrm{H}$ chondrites and is much lower for L chondrites, usually below $5 \%$. LL chondrites exhibit still lower fraction of the metallic phase.

Chondrites-type meteorites fall more or less uniformly over the Earth surface and thus provide samples to study weathering processes in very different environments. The outer crust of a large number of weathered ordinary chondrites shows the presence of weathering products such as akaganeite, goethite, lepidocrocite, maghemite and magnetite $[5,6]$.

The meteorite Košice fell on 28th of February 2010 near the town Košice in Slovakia and 77 small stone fragments with total weight of $4.3 \mathrm{~kg}$ were recovered.
In this work, Mössbauer spectroscopy is used for phase analysis of iron-containing compounds in meteorite with the aim to determine magnetic and non-magnetic fractions and to identify the type of chondrite.

\section{EXPERIMENTAL}

In order to investigate the heterogeneous composition of the fragment from Košice meteorite, the stone was scraped off to reduce the material to a powder. This process was performed stepwise beginning on the outer crust (sample 1) toward the center of the meteorite piece (sample 6 the most inner part). In this way, six powder samples originating from different depths of the stone were obtained. The last scraped layer reached to the depth of approximately $1 \mathrm{~mm}$ from the top of the sample. Mössbauer spectra of the powdered samples were recorded at room and liquid nitrogen temperatures using a Wissel Mössbauer spectrometer with the ${ }^{57} \mathrm{Co}(\mathrm{Rh})$ source in transmission geometry. The cryogenic system was adjusted for a long measurement time on the pressure of 10-2 Pa. Mössbauer spectra were evaluated by the CONFIT program [7]. In the fitting procedure, hyperfine parameters including isomer shift (IS), quadrupole splitting (QS), internal hyperfine magnetic field $\left(B_{\mathrm{hf}}\right)$ as well as relative absorption area $\left(A_{\text {rel }}\right)$ of individual components were acquired. The accuracy of the reported values is about $0.04 \mathrm{~mm} / \mathrm{s}$ for the isomer shift and quadrupole splitting, $0.5 \mathrm{~T}$ for the hyperfine field and about $2 \%$ for the relative absorption area. Mössbauer spectra of investigated meteorites consist of many overlapping subspectra. In order to distinguish between them correctly, a fitting

* Slovak University of Technology, Faculty of Electrical Engineering and Information Technology, Institute of Nuclear and Physical Engineering, Ilkovičova 3,812 19 Bratislava, Slovakia, jozef.sitek@stuba.sk 
model based on the superposition of magnetic and nonmagnetic components was applied.

Main constituent elements of both meteorites were also determined by X-ray fluorescence analysis. X-ray fluorescence spectra of meteorite was taken using Amptek X-123 Complete X-ray spectrometer with Si-PIN detector and analysed using Amptek ADMCA and XRF-FP program (Amptek 2012). The instrumentation system allows identifying elements with atomic number 11 and higher.

\section{RESULTS AND DISCUSSION}

The Mössbauer spectrum of the sample collected at room temperature is shown in Fig. 1 and the corresponding parameters of Mössbauer spectra are given in Tab. 1. The evaluation process showed that the magnetic fraction of the spectrum consists of two components. The first component represented by the sextet with hyperfine magnetic field $B_{\mathrm{hf}}$ of $33.6 \mathrm{~T}$ belongs to metallic phase containing iron in the form of kamacite.

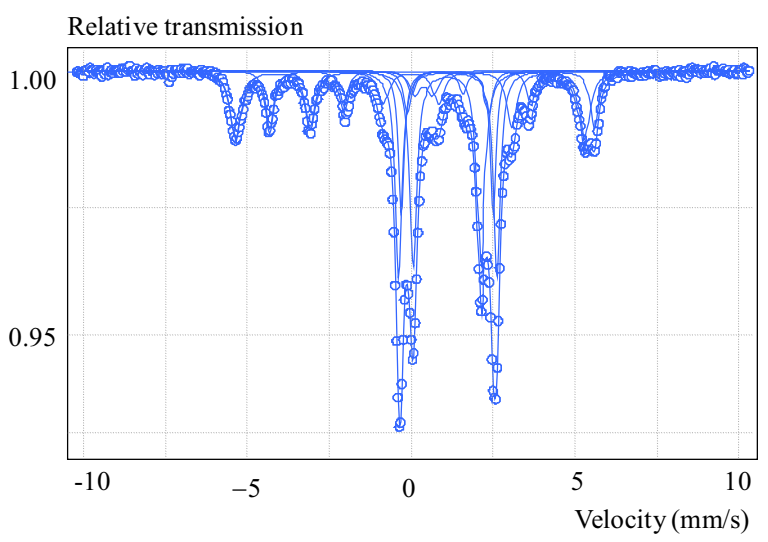

Fig. 1. Mössbauer spectrum of Košice meteorite measured at room temperature (RT)

Table 1. Parameters of Košice Mössbauer spectra measured at RT (above) and LNT (below)

\begin{tabular}{lcrrcc}
\hline Component & $\begin{array}{c}A_{\text {rel }} \\
(\%)\end{array}$ & $\begin{array}{c}I S \\
(\mathrm{~mm} / \mathrm{s})\end{array}$ & $\begin{array}{c}Q S \\
(\mathrm{~mm} / \mathrm{s})\end{array}$ & $\begin{array}{c}B_{\mathrm{hf}} \\
(\mathrm{T})\end{array}$ & $\begin{array}{c}\Gamma \\
(\mathrm{mm} / \mathrm{s})\end{array}$ \\
\hline kamacite & 23 & -0.02 & -0.02 & 33.6 & 0.39 \\
troilite & 13 & 0.73 & -0.16 & 31.3 & 0.30 \\
olivine & 39 & 1.12 & 2.95 & & 0.32 \\
pyroxene & 23 & 1.12 & 2.10 & & 0.30 \\
$\mathrm{Fe}^{3+}$ & 4 & 0.38 & 0.69 & & 0.40 \\
\hline
\end{tabular}

\begin{tabular}{lccrcc}
\hline Component & $\begin{array}{c}A_{\text {rel }} \\
(\%)\end{array}$ & $\begin{array}{c}I S \\
(\mathrm{~mm} / \mathrm{s})\end{array}$ & $\begin{array}{c}Q S \\
(\mathrm{~mm} / \mathrm{s})\end{array}$ & $\begin{array}{c}B_{\mathrm{hf}} \\
(\mathrm{T})\end{array}$ & $\begin{array}{c}\Gamma \\
(\mathrm{mm} / \mathrm{s})\end{array}$ \\
\hline kamacite & 16 & 0.05 & -0.03 & 34.1 & 0.46 \\
troilite & 14 & 0.76 & -0.14 & 32.1 & 0.38 \\
olivine & 43 & 1.16 & 3.03 & & 0.45 \\
pyroxene & 20 & 1.16 & 2.14 & & 0.42 \\
$\mathrm{Fe}^{3+}$ & 6 & 0.41 & 0.76 & & 0.54 \\
\hline
\end{tabular}

The presence of cobalt traces in this phase could be also considered. The second component represented by the sextet with $B_{\mathrm{hf}}$ of $31.3 \mathrm{~T}$ is related to troilite (FeS). The non-magnetic fraction of the Mössbauer spectra is evaluated as a superposition of three quadrupole doublets. Two doublets having a quadrupole splitting of 2.95 $\mathrm{mm} / \mathrm{s}$ and $2.10 \mathrm{~mm} / \mathrm{s}$ are embedded to evaluate two different $\mathrm{Fe}^{2+}$ phases, olivine and pyroxene, respectively. The third subspectrum employed to describe the nonmagnetic phase is a doublet with quadrupole splitting of about $0.69 \mathrm{~mm} / \mathrm{s}$ and an isomer shift typical for oxidized iron $\mathrm{Fe}^{3+}$. A trace amount of $\mathrm{Fe}^{3+}$ has been also found in many other meteorites [2], but it is usually less than 5 $\%$.

In order to confirm the fitting model, a measurement at LNT was carried out and the corresponding Mössbauer parameters also can be found in Tab. 1. The measurement confirmed phase composition of investigated sample and excluded presence of iron oxides in form of small superparamagnetic particles.

Another way to verify a fitting model of Mössbauer spectra applicable in case of powdered samples is mechanical separation of a magnetic and non-magnetic fraction. This procedure has been performed on sample 3 using hand magnet. The resultant Mössbauer spectrum of magnetically separated part of the sample is shown in Fig. 2 and the respective parameters can be found in Tab. 2. As expected, the spectrum has changed quantitatively and magnetic components dominate. An extremely high content of kamacite in comparison with troilite is obvious, as expected.

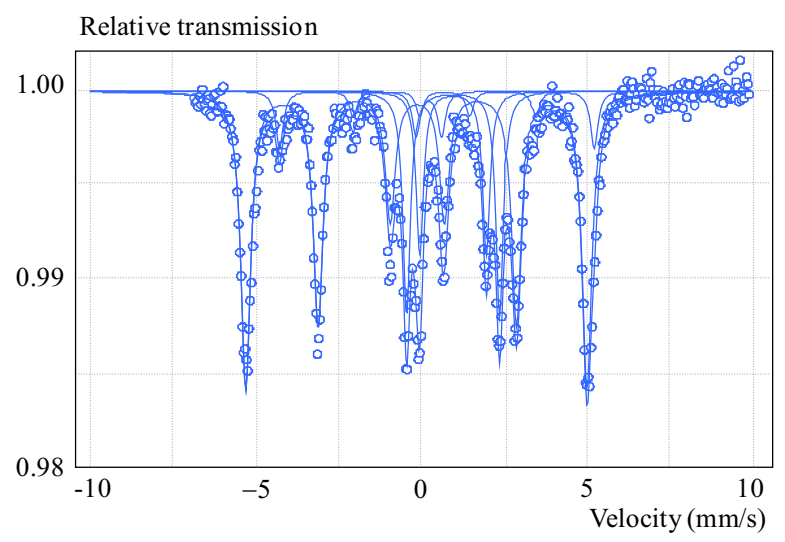

Fig. 2. Mössbauer spectrum of Košice meteorite after magnetic separation

Table 2. Mössbauer spectrum of Košice meteorite after magnetic separation

\begin{tabular}{lcrrcc}
\hline Component & $\begin{array}{c}A_{\mathrm{rel}} \\
(\%)\end{array}$ & $\begin{array}{c}I S \\
(\mathrm{~mm} / \mathrm{s})\end{array}$ & $\begin{array}{c}Q S \\
(\mathrm{~mm} / \mathrm{s})\end{array}$ & $\begin{array}{c}B_{\mathrm{hf}} \\
(\mathrm{T})\end{array}$ & $\begin{array}{c}\Gamma \\
(\mathrm{mm} / \mathrm{s})\end{array}$ \\
\hline kamacite & 61 & -0.01 & -0.01 & 33.6 & 0.37 \\
troilite & 8 & 0.74 & -0.23 & 31.0 & 0.28 \\
olivine & 16 & 1.12 & 2.94 & & 0.28 \\
pyroxene & 12 & 1.12 & 2.10 & & 0.28 \\
$\mathrm{Fe}^{3+}$ & 3 & 0.36 & 0.81 & & 0.29 \\
\hline
\end{tabular}


In order to follow the depth profile of the meteorite phase composition, six different samples of Košice meteorite were investigated. Room temperature Mössbauer spectrum of the sixth sample (inner layer) is presented in Fig. 3.

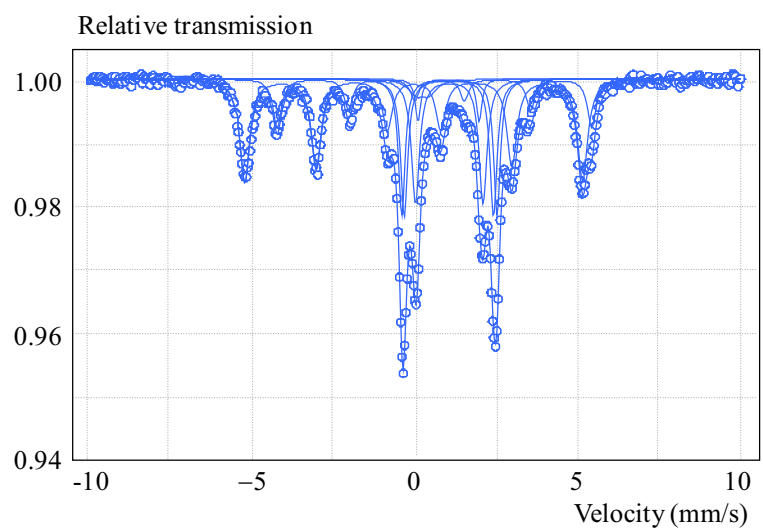

Fig. 3. Mössbauer spectrum of Košice meteorite (sample 6 the most inner part)

Table 3. Parameters of Košice Mössbauer spectrum (sample 6) measured at RT

\begin{tabular}{lccrcc}
\hline Component & $\begin{array}{c}A_{\text {rel }} \\
(\%)\end{array}$ & $\begin{array}{c}I S \\
(\mathrm{~mm} / \mathrm{s})\end{array}$ & $\begin{array}{c}Q S \\
(\mathrm{~mm} / \mathrm{s})\end{array}$ & $\begin{array}{c}B_{\mathrm{hf}} \\
(\mathrm{T})\end{array}$ & $\begin{array}{c}\Gamma \\
(\mathrm{mm} / \mathrm{s})\end{array}$ \\
\hline kamacite & 34 & 0.01 & -0.01 & 33.6 & 0.39 \\
troilite & 12 & 0.76 & -0.16 & 31.3 & 0.32 \\
olivine & 31 & 1.14 & 2.95 & & 0.31 \\
pyroxene & 19 & 1.14 & 2.10 & & 0.32 \\
$\mathrm{Fe}^{3+}$ & 4 & 0.38 & 0.76 & & 0.47 \\
\hline
\end{tabular}

The corresponding parameters of the spectrum can be found in Tab. 3. If compared with the spectrum and the respective parameters of sample 2 shown in Fig. 1 and Tab. 1, respectively; no qualitative differences are visible. Pronounced quantitative changes can be, however, observed in the relative absorption areas of magnetic and non-magnetic components. Mössbauer parameters also show that amount of the magnetic fraction corresponding to kamacite and troilite increases from the surface toward the centre of the investigated piece of meteorite. Within this magnetic component, the kamacite rapidly increased and troilite decreased toward the middle of the sample. Mössbauer parameters of all six investigated samples are summarized in Tab. 4, the most evident change in kamacite and troilite relative fractions are highlighted. The results obtained indicate that iron phases are not distributed uniformly inside the meteorite fragment. In the last column of Tab. 4, the ratio of olivine to pyroxene area is listed. According [2], olivine to pyroxene area of meteorites of the group chondrites $\mathrm{H}$ tend to occupy a zone below 1.9. As obvious from the olivine to pyroxene ratio values derived from fitting results, a good agreement with the known classification of Košice meteorite was reached.

\section{X-ray Fluorescence Analysis}

The X-ray fluorescence analysis is widely used to measure the elemental composition of different materials. This method proven useful also in the field of meteoritics because enables quickly, simply and non-destructively distinguish between different type of meteorites.

$\mathrm{XRF}$ analysis was employed to evaluate and compare the elemental composition of meteorites. The recommended energy range is from 1.5 to $25-40 \mathrm{keV}$ [8]. The spectrum of the meteorite is shown in Fig. 4. The major peaks correspond to characteristic radiation of iron ( $\mathrm{Fe}$ $\mathrm{K} \alpha$ and $\mathrm{Fe} \mathrm{K} \beta$ lines). The intensities of further peaks revealed in the spectra are considerably lower in comparison with iron and were attributed to $\mathrm{Ni}, \mathrm{Cr}, \mathrm{Mn}$, $\mathrm{Ca}, \mathrm{Si}, \mathrm{S}, \mathrm{Mg}$ and $\mathrm{Al}$, which all are typical constituents of chondrite-type meteorites. The presence of aluminium may, however, partly arise from materials near the detector. Argon peaks in the spectra are completely due to environmental interference (outside air).

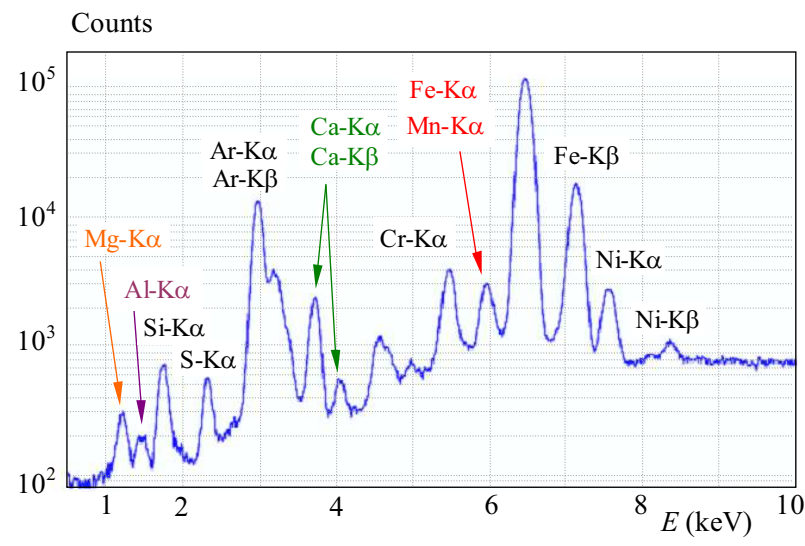

Fig. 4. X-ray fluorescence spectra of Košice meteorite

Table 4. Parameters of Mössbauer spectra of six samples of Košice meteorite: sample 1 outer layer, sample 6 inner part

\begin{tabular}{ccccccc}
\hline $\begin{array}{c}\text { Measuring } \\
\text { temperature }\end{array}$ & $\begin{array}{c}\text { olivine } \\
(\%)\end{array}$ & $\begin{array}{c}\text { pyroxene } \\
(\%)\end{array}$ & $\begin{array}{c}\text { troilite } \\
(\%)\end{array}$ & $\begin{array}{c}\text { kamacite } \\
(\%)\end{array}$ & $\begin{array}{c}\mathrm{Fe}^{3+} \\
(\%)\end{array}$ & $\begin{array}{c}\text { olivine } \\
\text { pyroxene }\end{array}$ \\
\hline 1, RT & 36 & 22 & 17 & 20 & 5 & 1.64 \\
$2, \mathrm{RT}$ & 39 & 23 & 13 & 23 & 4 & 1.70 \\
$3, \mathrm{RT}$ & 39 & 22 & 14 & 21 & 4 & 1.77 \\
$4, \mathrm{RT}$ & 36 & 18 & 12 & 29 & 5 & 2.00 \\
$5, \mathrm{RT}$ & 33 & 20 & 14 & 28 & 5 & 1.65 \\
$6, \mathrm{RT}$ & 31 & 19 & 12 & 34 & 4 & 1.63 \\
$2, \mathrm{LNT}$ & 43 & 20 & 14 & 16 & 6 & 2.15 \\
\hline
\end{tabular}




\section{CONCLUSIONS}

Košice meteorite has been analysed using Mössbauer spectroscopy technique and the resultant Mössbauer parameters confirmed that the meteorite belongs to the group of chondrites H. The samples of Košice meteorite have been prepared in powder form from different depths of the meteorite piece and the results point at the inhomogeneous composition of the investigated meteorite. The most pronounced change was the increasing ratio of kamacite to troilite toward the center of the meteorite. No weathering products have been found in the sample of Košice meteorite. X-ray fluorescence analysis was used to identify the main constituent elements of meteorite. The results showed the major content of iron, the concentration of other elements present in the samples varied slightly.

\section{REFERENCES}

[1] VIERA, V. W.-KNUDSEN, J. M.-ROY-POULSEN, N. O. CAMPSIE, J. : Mössbauer spectroscopy of Pyroxenes from Two Meteorites, Physica Scripta 27 (1983), 437-444.

[2] VERMA, H. C.-JEE, KAAVI-TRIPATHI, R. P.: Systematics of Mössbauer absorption areas in ordinary chondrites and applications to a newly fallen meteorite in Jodhpur, India Meteoritics and Planetary Science 38 No. 6 (2003), 963-967.

[3] Petrova, E. V.-OSHTRAKH, M. I.-GROKHOVSKY, V. I.-SEMIONKIN, V. A. : Study of metal grains extracted from chondrite Tsarev L5 using Mössbauer spectroscopy with high velocity resolution, Hyp. Int. 177 (2007), 81-87.

[4] OSHTRAKH, M. I.-PETROVA, E. V.-GROKHOVSKY, V. I.-SEMIONKIN, V. A.: Mössbauer spectroscopy with high velocity resolution in the study of ordinary chondrites, Hyp. Int. 186 (2008), 61-68.

[5] BLAND, P. A.-SEXTON, A. S.-JULL, A. J. T.-BEVAN, A. W. R.-BERRY, F. J.-THORNLEY, D. M.-ASTIN, T. R.-BRITT, D. T.-PILINGER, C. T.: Climate and rock weathering: A study of terrestrial age dated ordinary chondritic meteorites from hot desert regions, Geochimica et Cosmochimica Acta 62 No. 18 (1998), 3169-3184.
[6] LEE, M. R.-BLAND, P. A.: Dating climatic change in hot deserts using desert varnish on meteorite finds, Earth Planet. Sci. Lett. 206 (2003), 187-198.

[7] Ž, T.—JIRÁSKOVÁ, Y.: Surf. Interface Anal. 38 (2006), $710-714$.

[8] REDUS, R.-HUBER, A.-PANTAZIS, J.-PANTAZIS, T.SPERRY, D.: Design and performance of the X-123 compact X-ray and Gamma-ray spectroscopy system, Amptek, Inc. [cit: 2012-05-28]. Available on internet:

http://www.amptek.com/pdf/x123_ieee.pdf.

Received 24 September 2015

Jozef Sitek (Prof, Ing,DrSc) born in Záhorská Ves, Slovakia in 1944, graduated from the Faculty of Electrical Engineering, Slovak University of Technology, in 1966. He received his PhD degree in Applied Physics in 1974 and a DrSc degree in Physics of Condensed Matter in 1994. At present at he is Professor for Physical Engineering at the Institute of Nuclear and Physical Engineering, Faculty of Electrical Engineering and Information Technology.

Július Dekan (Ing, PhD) born in 1980 in Bratislava, Slovakia, graduated from the Faculty of Electrical Engineering and Information Technology, Slovak University of Technology in Bratislava in branch Electromaterial Engineering and received the PhD degree in Physical Engineering in 2010. Since 2008 he has worked as a researcher at the Institute of Nuclear and Physical Engineering of Faculty of Electrical Engineering and Information Technology.

Katarína Sedlačková (Ing, PhD), born in 1977 in Piešt'any, Slovakia, received her Master degree in Material Science Engineering from the Slovak University of Technology in Bratislava, the Faculty of Electrical Engineering and Information Technology, in 2001. She holds a PhD degree in Physical Engineering from the same university. At present, she is employed as an assistent at the Institute of Nuclear and Physical Engineering. Her research activities are currently focused on computer modelling of interaction of radiation with matter and on the use of spectroscopic methods in nuclear science (Mössbauer spectroscopy, XRF). 